\title{
Effect of probe characteristics on the subtractive hybridization efficiency of human genomic DNA
}

\author{
Marie J Archer*1, Nina Long² and Baochuan Lin
}

\begin{abstract}
Background: The detection sensitivity of low abundance pathogenic species by polymerase chain reaction (PCR) can be significantly enhanced by removing host nucleic acids. This selective removal can be performed using a magnetic bead-based solid phase with covalently immobilized capture probes. One of the requirements to attain efficient host background nucleic acids subtraction is the capture probe characteristics.

Findings: In this study we investigate how various capture probe characteristics influence the subtraction efficiency. While the primary focus of this report is the impact of probe length, we also studied the impact of probe conformation as well as the amount of capture probe attached to the solid phase. The probes were immobilized on magnetic microbeads functionalized with a phosphorous dendrimer. The subtraction efficiency was assessed by quantitative real time PCR using a single-step capture protocol and genomic DNA as target. Our results indicate that short probes (100 to $200 \mathrm{bp}$ ) exhibit the best subtraction efficiency. Additionally, higher subtraction efficiencies with these probes were obtained as the amount of probe immobilized on the solid phase decreased. Under optimal probes condition, our protocol showed a 90 - 95\% subtraction efficiency of human genomic DNA.

Conclusions: The characteristics of the capture probe are important for the design of efficient solid phases. The length, conformation and abundance of the probes determine the capture efficiency of the solid phase.
\end{abstract}

\section{Findings}

The presence of a large excess of non-target nucleic acids (NA), i.e. host genomic NA, sometimes is inevitable and can cause false positive or negative results when using molecular diagnostic technologies, such as PCR. The separation of background from low abundance pathogenic targets that coexist in complex matrices is necessary to ensure optimal detection sensitivity and specificity [1-4] and can be done using a solid phase with covalently attached probes. The characteristics of the probe, such as length, conformation and abundance on the solid phase, are of relevance in determining the capture efficiency. Therefore it is necessary to understand how such characteristics affect the capture efficiency in order to design efficient solid phases.

Information on the significance of probe diversification is limited. Most of the results reported to date deal with short single stranded oligonucleotides (20-70 nucleotides

* Correspondence: marie.archer@nrl.navy.mil

1 US Naval Research Laboratory, Center for Bio/Molecular Science \& Engineering, 4555 Overlook Avenue, S W, Washington, DC, 20375, USA Full list of author information is available at the end of the article (nt)) that may not be suitable for capturing genomic targets [2,5-10]. Mathematical models combined with experimental data, aimed at understanding the hybridization dynamics of DNA to surface-bound probes, have revealed that the kinetics are determined by the amount of probes immobilized on the surface, the length, the concentration, and the size of the target [6,11-15]. Zammateo et al. utilized capture probes of various lengths (56-255 base pair (bp)) immobilized on magnetic microparticles to characterize the capture efficiency of a $435 \mathrm{bp}$ target. They found that the longer probes, which correlated with higher immobilization efficiency, exhibited the best subtraction efficiency and determined the reaction yield. However, these observations were based solely on the size of the probe [16]. These results differ from the observations of other studies which suggest that low probe densities favour hybridization kinetics and that there is a tradeoff between the length of the probes and their density on the surface $[7,11,13]$. These contradictory results highlight the complexity in which solid phase hybridization occurs and further support the need to optimize the capture probe depending on particular application needs. 
In this work, we focused on the effects of the length, conformation and the amount of probe on the selective capture of human genomic DNA using a previously developed magnetic bead based solid phase that enables capture of genomic targets in a single step [17-19]. Capture probes of various lengths were synthesized using strand displacement, isothermal amplification and PCR. Our results demonstrated that better capture efficiency was achieved using shorter probes and correlates to the amount of immobilized probes. Furthermore, fragmented human genomic DNA targets (100-5000 bp) can be captured efficiently even with probes as short as 100 to 200 bp. This finding disagrees with the existing literature which suggests that the target should be shorter than 100 bp for efficient solid phase hybridization [11].

\section{Methods}

\section{Magnetic bead based solid support preparation}

Preparation and functionalization of magnetic beads with generation 4.5 phosphorous dendrimer was as described in a previous publication [17] with slight modifications. Briefly, the magnetic beads were prepared in batch mode and the volumes of solvent used were adjusted accordingly [see Additional file 1 for details].

\section{Preparation of capture probes}

Capture probes were prepared by three different methods: Sequenase DNA Polymerase, Klenow fragment, and PCR. The Sequenase probes were prepared in a $30 \mu \mathrm{l} \mathrm{vol-}$ ume containing $40 \mathrm{mM}$ Tris- $\mathrm{HCl}$ (pH 7.5), $20 \mathrm{mM} \mathrm{MgCl}_{2}$, $50 \mathrm{mM} \mathrm{NaCl}, 7 \mu \mathrm{M}$ Primer D [See additional file 1: Supplemental Table S1], $0.67 \mathrm{mM}$ dNTPs, $13 \mathrm{U}$ of Sequenase $^{\mathrm{Tm}}$ Version 2.0 DNA Polymerase (USB, Cleveland, $\mathrm{OH})$, and $4 \mu \mathrm{g}$ of COT human DNA with preliminary denaturation at $95^{\circ} \mathrm{C}$ for $2 \mathrm{~min}$., followed by incubation at $10^{\circ} \mathrm{C}$ for $5 \mathrm{~min}$., then at $37^{\circ} \mathrm{C}$ for $60 \mathrm{~min}$. The Klenow probes were prepared in a $50 \mu \mathrm{l}$ reaction volume containing $10 \mathrm{mM}$ Tris- $\mathrm{HCl}$ (pH 7.9), $10 \mathrm{mM} \mathrm{MgCl} 2,50 \mathrm{mM}$ $\mathrm{NaCl}, 1 \mathrm{mM}$ DTT, $20 \mu \mathrm{M}$ primer D, $0.2 \mathrm{mM}$ dNTPs, $10 \mathrm{U}$ of Klenow fragment ( $3^{\prime} \mathrm{T} 5^{\prime}$ exo-$^{-}$) (NEB, Ipswich, MA) with initial denaturation at $95^{\circ} \mathrm{C}$ for $5 \mathrm{~min}$. followed by immediate cool down at $4^{\circ} \mathrm{C}$, incubation at $37^{\circ} \mathrm{C}$ for 6 hours and enzyme inactivation at $75^{\circ} \mathrm{C}$ for $20 \mathrm{~min}$. For reactions using Sequenase DNA polymerase and Klenow fragment, the enzymes and the dNTPs were added after the denaturation step. The PCR probes were prepared in a $50 \mu$ reaction volume with GoTaq DNA Polymerase (Promega, Madison, WI) using $2 \mu \mathrm{M}$ Primer NL and 0.8 $\mu \mathrm{M}$ Primer NLN [See additional file 1: Supplemental Table S1] and $400 \mathrm{ng}$ of human genomic DNA (Roche, Indianapolis, IN) as template. The amplification reaction was carried out with preliminary denaturation at $94^{\circ} \mathrm{C}$ for $2 \mathrm{~min}$. followed by 40 cycles of $94^{\circ} \mathrm{C}$ for $30 \mathrm{~s}, 40^{\circ} \mathrm{C}$ for 30 $\mathrm{s}, 50^{\circ} \mathrm{C}$ for $30 \mathrm{~s}$, and $72^{\circ} \mathrm{C}$ for $2 \mathrm{~min}$., and a final extension step at $72^{\circ} \mathrm{C}$ for $7 \mathrm{~min}$.

All the products were purified using QIAquick PCR purification kit (Qiagen, Valencia, CA) following the manufacturer's instructions. Prior to immobilization, the PCR probes were denatured at $95^{\circ} \mathrm{C}$ for $5 \mathrm{~min}$. and cooled to $4^{\circ} \mathrm{C}$. Verification of the probes as single strands was performed using a Qubit fluorometer with the QuantIT $^{\mathrm{TM}}$ ssDNA assay kit (Invitrogen, Carlsbad, CA).

\section{Immobilization of capture probes}

The probe immobilization was performed as described in a previous publication with minor modifications [17]. Briefly, magnetic beads functionalized with a generation 4.5 phosphorous dendrimer were re-suspended in $750 \mu \mathrm{l}$ of $0.3 \mathrm{M}$ sodium phosphate buffer at $\mathrm{pH} 9.0\left(\mathrm{Na}_{2} \mathrm{HPO}_{4}\right)$ and sonicated for 10-15 seconds to ensure the beads were dispersed. The beads were incubated overnight at room temperature with three additional buffer changes. Immobilization was performed at room temperature by adding $150 \mu \mathrm{l}$ of capture probe solution at a concentration of 3, 6, 9, 12 and $15 \mathrm{ng} / \mu \mathrm{l}$ with periodic re-suspension. After immobilization, reduction and blocking for non-specific adsorption was carried out as previously described [17] with slight modifications in the sodium borohydride solution (25 mg instead of $12.5 \mathrm{mg}$ of $\mathrm{NaBH}_{4}$ was used) and incubation time (extended to $15 \mathrm{~min}$ ). The beads were washed with $0.2 \%$ SDS, resuspended in $300 \mu \mathrm{l}$ of stripping buffer $(1 \times \mathrm{SSC} / 0.1 \% \mathrm{SDS})$ and incubated for 20-24 min. at $95^{\circ} \mathrm{C}$ with one buffer exchange and re-suspension at the half way point. The beads were then washed with nuclease free water pre-warmed at $95^{\circ} \mathrm{C}$ for 20-24 min., with re-suspension at the half way point followed by a $30 \mathrm{~min}$. wash in $5 \times \mathrm{SCC} / 0.1 \% \mathrm{SDS}$ and $0.6 \times$ $\mathrm{SCC} / 0.03 \% \mathrm{SDS}$ at $55^{\circ} \mathrm{C}$ with re-suspension at the half way point. Finally, the beads were pooled into $1200 \mu \mathrm{g}$ aliquots in $0.1 \%$ SDS and stored at $4^{\circ} \mathrm{C}$ after discarding the SDS solution. The immobilization efficiency was determined to be between $95-98 \%$ by quantification of the supernatant using a NanoDrop ND-1000 fluorospectrometer (NanoDrop Technologies, Wilmington, DE) as previously described [17]. Magnetic beads with no probes were prepared in an identical manner and used as controls.

\section{Subtractive hybridization assays}

Human genomic DNA was fragmented by McrBC (NEB) supplemented with $0.125 \mathrm{ug} / \mathrm{ul}$ of BSA and used as the target. The subtractive hybridization assays were performed as described previously with the following modifications [See additional file 1: Supplemental Figure S1]. The reaction volume was changed to $250 \mu \mathrm{l}$ and the hybridization buffer $(200 \mu$ l per sample) contained 3.375 
M TMAC $/ 0.11 \%$ SDS pre-warmed to $37^{\circ} \mathrm{C}$. The reactions were carried out in Thermomixer (Eppendorf, Westbury, $\mathrm{NY}$ ) with denaturing at $97^{\circ} \mathrm{C}$ for $20 \mathrm{~min}$. and annealing at $60^{\circ} \mathrm{C}$ for $90 \mathrm{~min}$. After incubation, the supernatant was collected and the beads were washed with $100 \mu \mathrm{l}$ each of $2 \times$ SSC/0.1\%SDS and $0.1 \times$ SCC/0.1\%SDS. All supernatants were collected and a second magnetic separation was performed to eliminate any bead carryover. The supernatants were ethanol precipitated and resuspended in $10 \mathrm{mM}$ Tris- $\mathrm{HCl}$ at $\mathrm{pH} 8.5$.

\section{Quantitative real-time PCR}

Quantitative real-time PCR (qPCR) was performed using the MyiQ ${ }^{\text {mw }}$ real-time PCR detection system with $\mathrm{iQ} \mathrm{SYBR}$ Green Supermix (Bio-Rad Laboratories, Inc., Hercules, $\mathrm{CA}$ ) according to the manufacturer's recommended protocol. The primers used and PCR conditions are listed in supplemental information [See additional file 1: Supplemental Table S1]. All qPCR results were reported in terms of genome copy concentration per microliter using an external standard curve with known concentration of ACTB.

\section{Results and discussion}

Three different capture probes for human genomic DNA (hgDNA) were synthesized by isothermal amplification ("Klenow probes"), strand displacement ("Sequenase probes") and polymerase chain reaction ("PCR probes"). Gel electrophoresis of the probes shows a length variation from $\sim 100$ - $300 \mathrm{bp}$ for the Klenow probes to $\sim 200$ $600 \mathrm{bp}$ for the Sequenase and $\sim 300-800$ bp for PCR probes (Figure 1). To compare the subtraction efficiency, the probes were covalently immobilized on magnetic microbeads and subtraction was performed using a previously developed single step protocol [See additional file 1: Supplemental Figure S1]. The supernatant containing the remnant DNA was precipitated and analyzed with qPCR, and the subtraction efficiency for each probe type was compared (Table 1). The results indicated that the Klenow probes showed the best subtraction efficiency with less experimental variation, while the Sequenase probes showed similar subtraction efficiency with higher variations. The PCR probes showed the lowest subtraction efficiency in comparison to the Klenow and Sequenase probes. The results also revealed a general trend that reduction in the amount of probe enhanced the subtraction efficiency. Additional experiments performed at higher probe densities (up to $30 \mathrm{ng} / \mu \mathrm{l}$ ) using various buffer systems indicated that the subtraction efficiency decreases as the amount of probe increases (data not shown).

Given the low subtraction efficiency of PCR probes, further characterizations were undertaken with only the Klenow and Sequenase probes. Further experiments confirmed the observation that, reduction in the amount of probe enhanced the subtraction efficiency with Klenow probes which exhibited less experimental variations (Figure 2).

These results indicated that the probe length plays a major role in the subtraction efficiency and that the shorter probes provided better subtraction efficiency. This is probably due to the fact that longer probes form secondary structures (hairpin or loop) which are thought to negatively affect the hybridization efficiency in solution and solid phase even with oligonucleotides as short as $60 \mathrm{nt}[14,15]$. They also represent a more complex scenario since bending induced by electrostatic interactions and intermolecular hybridization can occur and affect hybridization [20]. Our results also indicate that a lower input concentration $(3 \mathrm{ng} / \mu \mathrm{l})$ of shorter probes $(\sim 100$ $200 \mathrm{bp}$ ) can be utilized to subtract up to $1000 \mathrm{ng}$ of hgDNA. Larger spacing between the probes reduces steric interference and facilitates diffusion of the targets which is further enhanced by the gradual decrease in temperature and the intermittent mixing. These results contradict the observations by Chan et al. who determined that the rate of hybridization per unit area was equally efficient, regardless of the probe size, if there was proper spacing and as long as the target was between 100 to $160 \mathrm{bp}$ [11]. However, these simulations did not con-

Table 1: Subtraction efficiencies of human genomic DNA using three different types of probes

\begin{tabular}{ccc}
\hline $\begin{array}{c}\text { Concentration } \\
(\mathbf{n g} / \boldsymbol{\mu l})\end{array}$ & $\begin{array}{c}\text { Subtraction efficiency } \\
(\%) \text { PCR probes }\end{array}$ & $\begin{array}{c}\text { Subtraction efficiency } \\
(\%) \text { Sequenase probes }\end{array}$ \\
\hline 12 & $66 \pm 6$ & $88 \pm 3$ \\
\hline 6 & $80 \pm 1$ & $77 \pm 25$ \\
\hline 3 & $82 \pm 6$ & $93 \pm 5$ \\
\hline
\end{tabular}

The subtractions were performed in duplicate experiments. 


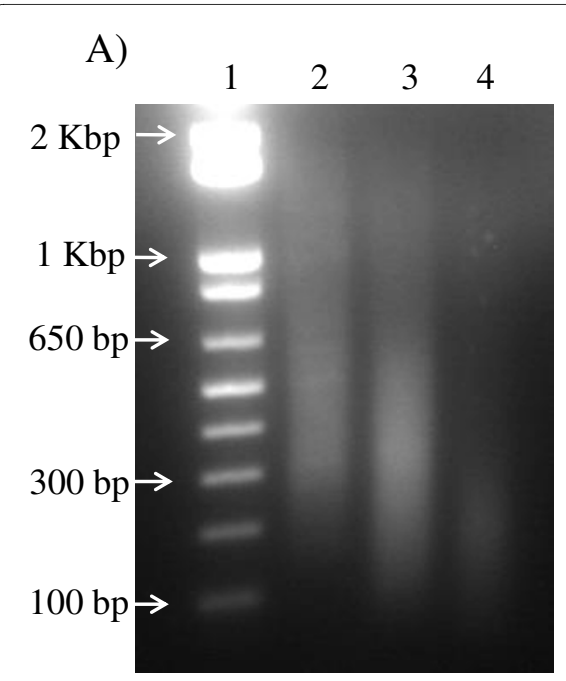

B)

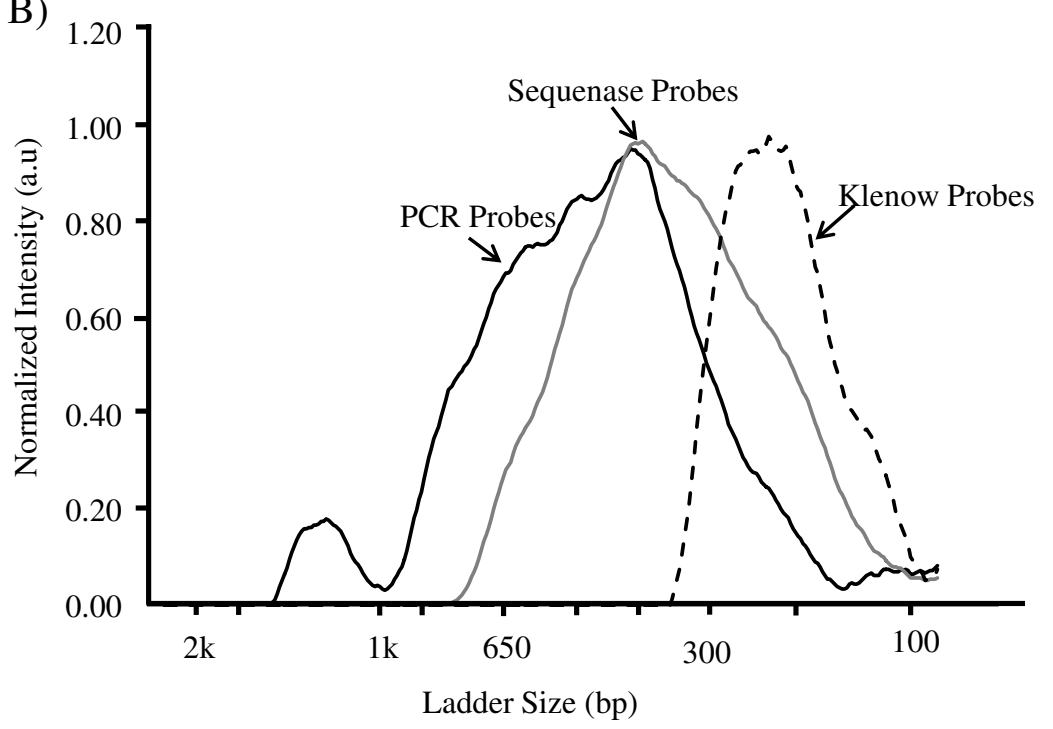

Figure 1 Capture probe characterization. (A) Representative image of different capture probes. Lane 1, molecular weight marker; lane 2, PCR probes; lane 3, probes synthesized by strand displacement; lane 4, probes generated by isothermal amplification. The products were run on a 1.2\% TAE agarose gel and visualized by ethidium bromide staining. (B) Histogram showing the distribution of the sizes of the capture probes. The corresponding molecular weight marker sizes are indicated in the $x$-axis.

sider secondary structures or targets of variable molecular sizes.

Interestingly, the Sequenase probes contain probes sizes similar to the Klenow probes (100 to $200 \mathrm{bp}$ ) (Figure $1)$, however, the capture efficiency was lower and more variable. This may reflect the fact that longer probes represent the majority within the Sequenase generated probes. In this case the hybridization would be domi-

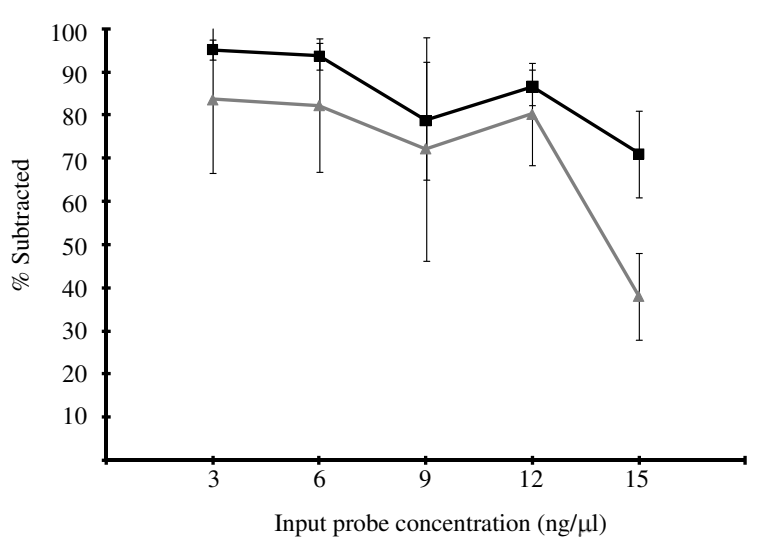

Figure 2 Comparison of subtraction efficiency between the Klenow and the Sequenase probes. The Klenow (solid black) and the Sequenase (solid grey) probes were further evaluated for their subtraction efficiency. The $Y$-axis shows \% subtraction, and the $\mathrm{x}$-axis indicates the input probes concentration. These experiments comprised at least 5 subtractions and the GPCR was performed in triplicate. Error bars correspond to the standard deviation of the mean. nated by these longer fragments which exhibit an inherently lower subtraction efficiency than do shorter probes. Even if short probes are present, diffusion of the targets to these sites might be hindered by secondary structure or steric interference. In addition to length, the sequence of the probes is another parameter to consider since it influences the structure of the probes $[14,15,21]$. However, we have not performed sequencing analysis and we cannot discuss in further detail this particular parameter.

\section{Conclusions}

In conclusion, we have investigated the effect of probe length, conformation and amount on the solid phase capture efficiency of human genomic DNA. In contrast with the published literature, our results indicate that, probes as short as 200 bp can capture between 500-1000 ng of human genomic DNA (100 and $5000 \mathrm{bp}$ ). Longer probes (600-1000 bp) exhibited lower subtraction efficiency ( $10 \%$ difference) with greater variability. Secondary structure and steric interference might be responsible for these differences. In all cases, a lower amount of immobilized probe on the magnetic beads correlated with an enhanced performance. The results presented here are of relevance for the design of efficient solid phases for the selective capture of genomic targets.

\section{List of Abbreviations}

NA: nucleic acids; SDS: sodium dodecyl sulfate; SSC: standard sodium citrate; PCR: Polymerase chain reaction; TMAC: tetramethylammonium chloride. 


\section{Additional material}

Additional file 1 Supplemental material to the methods. Details on the magnetic bead bases solid support preparation, hybridization capture assays (Figure S1) and primer sequences and PCR conditions (Table S1).

\section{Competing interests}

There are two pending patent applications, one for preparation and functionalized of magnetic beads and one for genomic DNA subtraction protocol, that are related to this article. Both $\mathrm{MJA}$, and $\mathrm{BL}$ are listed as inventors of these two patent applications.

\section{Authors' contributions}

MJA participated in the concept development, characterization and fabrication the solid phase, and drafting the manuscript. NL performed the probes synthesis and subtraction experiments. BL participated in the concept development, performing quantitative real time PCR analysis, and drafting the manuscript.

\section{Acknowledgements}

This study was sponsored by the Defense Threat Reduction Agency. We thank Dr. Nazir Barekzi and Mr. Paul Charles for critically reviewing the manuscript. We also thank Dr. Thomas O'Shaugnessy for his assistance in generating the capture probe histograms. The views expressed here are those of the authors and none are to be construed as those of the Defense Threat Reduction Agency, the U. S. Navy, the U. S. Department of Defense, or the U. S. Government at large.

\section{Author Details}

1 US Naval Research Laboratory, Center for Bio/Molecular Science \& Engineering, 4555 Overlook Avenue, S W, Washington, DC, 20375, USA and 2NOVA Research Inc, 1900 Elkin St, Suite 230, Alexandria, VA, 22308, USA

Received: 18 December 2009 Accepted: 20 April 2010 Published: 20 April 2010

\section{References}

1. Millar DS, Withey SJ, Tizard MLV, Ford JG, Hermon-Taylor J: Solid phase hybridization capture of low-abundance target DNA sequences: Applications to the polymerase chain reaction detection of Mycobacterium Paratuberculosis and Mycobacterium avium subsp. silvaticum. Anal Biochem 1995, 226:325-330.

2. Mangiapan G, Vokurka M, Schouls L, Cadranel J, Lecossier D, Van Embden J, Hance AJ: Sequence capture-PCR improves detection of mycobacterial DNA in clinical specimens. J Clin Microbiol 1996, 34:1209-1215.

3. Pradel N, Leroy-Setrin S, Joly B, Livrelli V: Genomic subtraction to identify and characterize sequences of shiga toxin producing Escherichia coli O91:H21. Appl Environ Microbiol 2002, 68:2316-2325.

4. Boni J, Shah C, Flepp M, Luthy R, Schupbach J: Detection of low copy numbers of HIV-1 proviral DNA in patient PBMCs by a high-input, sequence capture PCR (Mega-PCR). J Med Virol 2004, 72:1-9.

5. Day PJR, Flora PS, Fox JE, Walker MR: Immobilization of polynucleotides on magnetic particles. Factors influencing hybridization efficiency. Biochem J 1991, 278:735-740.

6. Stevens PW, Henry MR, Kelso DM: DNA hybridization on microparticles: determining capture-probe density and equilibrium dissociation constants. Nucleic Acids Res 1999, 27:1719-1727.

7. Peterson AW, Heaton RJ, Georgiadis RM: The effect of surface probe density on DNA hybridization. Nucleic Acids Res 2001, 29:5163-5168.

8. Zeng J, Almadidy A, Watterson J, Krull UJ: Interfacial hybridization kinetics of oligonucleotides immobilized on fused silica surfaces. Sens Actuators B 2003, 90:68-75

9. Yeung SW, Hsing IM: Manipulation and extraction of genomic DNA form cell lysate by functionalized magnetic particles for lab on a chip applications. Biosens Bioelectron 2006, 21:989-997.

10. Parham NJ, Picard FJ, Peytavi R, Gagnon M, Seyrig G, Gagne PA, Boissinot $M$, Bergeron MG: Specific magnetic bead-based capture of genomic DNA from clinical samples: application to the detection of group B Streptococci in vaginal/anal swabs. Clin Chem 2007, 53:1570-1576.
11. Chan V, Graves DJ, McKenzie SE: The biophysics of DNA hybridization with immobilized oligonucleotide probes. Biophys J 1995, 69:2243-2255

12. Okahata Y, Kawase M, Niikura K, Ohtake F, Furusawa H, Ebara Y: Kinetic Measurements of DNA Hybridization on an OligonucleotideImmobilized 27-MHz Quartz Crystal Microbalance. Anal Chem 1998 70:1288-1296.

13. Hagan MF, Chakraborty AK: Hybridization dynamics of surface immobilized DNA. J Chem Phys 2004, 120:4958-4968.

14. Chien FD, Liu JS, Su HJ, Kao LA, Chiou CF, Chen WY, Chen SJ: An investigation into the influence of secondary structures on DNA hybridization using surface Plasmon resonance biosensing. Chem Phys Lett 2004, 397:429-434.

15. Gao Y, Wolf LK, Georgiadis RM: Secondary structure effects on DNA hybridization kinetics: a solution versus surface comparison. Nucleic Acids Res 2006, 34:3370-3377.

16. Zammateo N, Alexandre I, Ernest I, Le L, Brancart F, Remacle J: Comparison between microwell and bead supports for the detection of human cytomegalovirus amplicons by sandwich hybridization. Anal Biochem 1997, 253:180-189.

17. Archer MJ, Lin B, Wang Z, Stenger DA: Magnetic bead-based solid phase for selective extraction of genomic DNA. Anal Biochem 2006, 355:285-297.

18. Archer MJ, Lin B, Stenger DA: Selective solid phase for capture of genomic nucleic acids in complex mixtures in a single step. 2007. U.S Patent Application 11/751,096

19. Archer MJ, Stenger DA, Lin B: Development and characterization of a solid phase for single step enrichment of pathogenic targets. The Open Analytical Chemistry Journal 2008, 2:47-54.

20. Fenley MO, Olson WK, Tobias I, Manning GS: Electrostatic effects in short superhelical DNA. Biophys Chem 1994, 50:255-271.

21. Matsumoto A, Olson WK: Sequence-dependent motions of DNA: A normal mode analysis at the base pair level. Biophys J 2002, 83:22-41.

doi: 10.1186/1756-0500-3-109

Cite this article as: Archer et al., Effect of probe characteristics on the subtractive hybridization efficiency of human genomic DNA BMC Research Notes 2010, 3:109

\section{Submit your next manuscript to BioMed Centra and take full advantage of:}

- Convenient online submission

- Thorough peer review

- No space constraints or color figure charges

- Immediate publication on acceptance

- Inclusion in PubMed, CAS, Scopus and Google Scholar

- Research which is freely available for redistribution
C) Biomed Central 